\title{
Como educar sem contribuir para um novo Auschwitz?
}

IBAÑEZ, César Augusto ${ }^{1}$

\section{RESUMO}

O artigo apresenta um ensaio analítico sobre o que poderia ser feito, em termos de ações educacionais, no sentido de se evitar um novo fracasso civilizatório, como o ocorrido em Auschwitz. Busca aprender do paradoxo vivenciado no Terceiro Reich: uma sociedade alemã, tão bem-educada e culta, ter descambado para a barbárie. Para tanto, teve como linha central a preocupação de Adorno sobre esse paradoxo, dialogando com autores como: Gramsci, Le Goff, Freire e Fanon. Refletiu-se acerca dos vários aspectos que envolveram Auschwitz, e de que maneira uma formação humana integral, poderia contribuir para evitar uma nova barbárie. Analisamos orientações presentes nas DCNs para o Ensino Médio, e para a Educação em Direitos Humanos; nos Cadernos de Formação de Professores do Ensino Médio; abordando a politecnia ou omnilateralidade de Gramsci. Concluiu-se constatando 0 quanto as circunstâncias de Auschwitz ainda têm a nos ensinar, assim como, o quanto o tema é atual; e que algo pode ser feito na educação, no sentido de se buscar evitar um novo Holocausto.

Educação. Emancipação. Políticas Públicas. Auschwitz.

\section{How to educate without contributing to a new Auschwitz?}

\section{ABSTRACT}

The article presents an analytical essay on what could be done, in terms of educational activities, in order to avoid a new civilizatory failure, like happened in Auschwitz. Seeks on learning from the paradox experienced in the Third Reich: a German society, well educated and cultured, to have collapsed into barbarism. Therefore, Adorno's concern about this paradox was the central line, in dialogue with authors such as Gramsci, Le Goff, Freire, and Fanon. We reflected upon various aspects that involved Auschwitz, and how an integral human formation could contribute to avoiding new barbarism. We analyzed guidelines present in the National Curricular Guidelines (DCN) for High School, and Human Rights Education; in the High School Teacher Training Material; addressing Gramsci's polytechnic or omnilaterality. We concluded by verifying that the circumstances in Auschwitz have a lot to teach us, as well as, how current the topic is; and, regarding education, that something can be done in order to avoid a new holocaust.

\footnotetext{
1 Doutorando em Educação no PPGE da UFPR, professor da Rede Pública de Ensino do Paraná. E-mail: cesarabnz@gmail.com. Lattes: http://lattes.cnpq.br/8084768778203006. ORCID: https://orcid.org/0000-0003-2131-882X.
} 
Education. Emancipation. Public Policy. Auschwitz.

\section{¿Cómo educar sin contribuir con un nuevo Auschwitz?}

\section{RESUMEN}

El artículo presenta un ensayo analítico sobre lo que podría hacerse, en términos de acciones educativas, para evitar un nuevo fracaso de civilización, como lo que sucedió en Auschwitz. Busca aprender de la paradoja experimentada en el Tercer Reich: una sociedad alemana, tan bien educada y culta, que, así mismo, descendió a la barbarie. En ese sentido, tuvimos como línea central la preocupación de Adorno acerca de esta paradoja, dialogamos con autores como: Gramsci, Le Goff, Freire y Fanon. Reflexionamos sobre los diversos aspectos que involucraron a Auschwitz y cómo una formación humana integral podría contribuir a evitar una nueva barbarie. Analizamos las pautas presentes en las DCN para la educación secundaria y para la educación en derechos humanos; en los cuadernos de formación de docentes de secundaria; abordando la politécnica u omnilateralidad de Gramsci. Concluimos averiguando lo mucho que nos tienen que enseñar las circunstancias de Auschwitz, la actualidad del tema; y que se puede hacer algo en educación, en el sentido de buscar evitar un nuevo Holocausto.

Educación. Emancipación. Políticas Públicas. Auschwitz.

\section{Come educare senza contribuire a una nuova Auschwitz?}

\section{SINTESE}

L'articolo presenta un saggio analitico su cosa si potrebbe fare, in termini di azioni educative, per evitare un nuovo fallimento della civiltà, come quello che è successo ad Auschwitz. Cerca di imparare dal paradosso sperimentato nel Terzo Reich: una società tedesca, così ben educata e istruita, che allo stesso modo discese nella barbarie. In questo senso, abbiamo avuto la preoccupazione di Adorno per questo paradosso come linea centrale, abbiamo parlato con autori come: Gramsci, Le Goff, Freire e Fanon. Riflettiamo sui vari aspetti che hanno coinvolto Auschwitz e su come una formazione umana integrale possa contribuire a evitare una nuova barbarie. Analizziamo le linee guida presenti nel DCN per l'istruzione secondaria e per l'educazione ai diritti umani; nei quaderni di formazione degli insegnanti delle scuole superiori; rivolgendosi al politecnico $o$ onnilateralità di Gramsci. Concludiamo scoprendo quanto le circostanze di Auschwitz devono insegnarci, l'attualità della materia; e che qualcosa può essere fatto nell'educazione, nel senso di cercare di evitare un nuovo Olocausto.

Istruzione. l'emancipazione. Politiche pubbliche. Auschwitz.

\section{INTRODUÇÃO}

REVISTA

interritórios
Interritórios | Revista de Educação

Universidade Federal de Pernambuco,

Caruaru, BRASIL | V.6 N.10 [2020] 
Tomando como base a máxima de Adorno: "A exigência que Auschwitz não se repita é a primeira de todas para a educação. De tal modo ela precede quaisquer outras que creio não ser possível nem necessário justificá-la" (1995, p.119), pretendemos neste trabalho refletir no dilema que ela nos sugere, no tocante aos princípios e propósitos da educação contemporânea. Mais especificamente, significa dizer: quais os aspectos devem ser ponderados na educação, a fim de produzir uma sociedade sim, culta, ilustrada, todavia, convicta e consciente da necessidade de um mundo em paz, mais empático e mais justo?

Quando decidimos tratar desse tema, a educação após Auschwitz, confessamos que, de início, hesitamos um pouco. Ocorria-nos assim: será que é viável, será que vale a pena? Provavelmente os possíveis leitores acharão este tema um tanto que ultrapassado, sem eco com a realidade. Todavia, quando praticamente já havíamos concluído o artigo, para nossa surpresa, tomamos contato com a seguinte notícia: "Secretário de Cultura é demitido após copiar discurso de ministro nazista ${ }^{2}$." Fato este que, além, é claro, de ter-nos deixado tremendamente estupefatos, de certa forma, acabou nos sendo útil. Pois deunos a convicção que estava nos faltando, acerca da relevância e indispensabilidade das reflexões, como as que aqui nos propusemos. Confirmou o quanto ainda é atual e necessário se tratar de um tema tão impactante como este, em nossos trabalhos.

Como ponto de partida, temos que ter em mente o tremendo paradoxo demonstrado pela sociedade alemã do Terceiro Reich, isto é, como pôde, uma sociedade que, em tese, era tão civilizada e tão culta, ter sido cúmplice de uma das páginas mais terríveis da história da humanidade? Com certeza, tal contexto sempre servirá de ensinamento, com lições a serem tiradas pela sociedade brasileira, e pela humanidade como um todo, sem distinção de oriente ou ocidente, hemisfério norte ou sul.

Ao direcionar nosso olhar sobretudo para a realidade brasileira, infelizmente, a impressão que temos é a de que nossa sociedade, praticamente, não aprendeu muita coisa com os erros que culminaram em Auschwitz. Observamos em nosso contexto atual uma série de manifestações ofensivas e retrógradas, expressadas em valores, posturas ou concepções, que nos confirmam do baixo aprendizado adquirido da sociedade alemã, da época hitleriana.

Atitudes tais como: misoginia, preconceito pela opção sexual, discriminação pelas pessoas idosas, intolerância religiosa e pela opinião política, xenofobia, etnocentrismo, racismo, aporofobia, rejeição ao Estado de bem-estar

${ }^{2}$ https://www1.folha.uol.com.br/ilustrada/2020/01/secretario-de-bolsonaro-e-exonerado-apospronunciamento-semelhante-a-de-ministro-de-hitler.shtml. 
social, aversão às políticas de ação afirmativa ou compensatórias, endeusamento do mercado, fascínio pelo capitalismo, culto à meritocracia, demonização da política, desprezo pela democracia, escárnio com os direitos humanos, descaso com o politicamente correto, censura à manifestação artística e de pensamento, patrulhamento ou vigilância à liberdade de ensino, perseguição medieval aos intelectuais; entre tantas outras formas de se agredir, gerar conflito ou clima de discórdia, constatamos sendo realizadas abundantemente, em nosso meio.

A princípio, tais manifestações acabam expressando ou induzindo a violência mais no plano verbal. Todavia, elas possuem um grande potencial para desencadearem a violência física, propriamente dita. Embora, evidentemente, não podemos negar que a violência no campo do preconceito, da intolerância, e do ódio transmitido de forma verbal, também produzem consequências nefastas. Como se sabe, ela tem poder para afetar uma pessoa, em muitas das vezes, com intensidade e consequência, igual ou pior, no campo psicológico e emocional, como se tivesse ocorrido uma violência física.

Pensando em termos de violência física, podemos exemplificar sua prática em diversos contextos: em maus tratos com crianças e idosos, em feminicídios, em estupros, em violência sexual de toda ordem, em práticas de crueldade para com os animais, em homicídios gratuitos, em latrocínios, em mortes nas guerras e em crimes de guerra, nas piores formas de barbárie e de tortura, praticadas com requinte de crueldade.

Não poderíamos deixar de relacionar aqui, a forma de violência definida por escravidão, que acontece ainda hoje em nosso mundo contemporâneo. Ela pode ocorrer da forma mais próxima à tradicional, identificada no trabalho escravo exercido por crianças, adultos, indivíduos do seu próprio país, e principalmente por imigrantes. São muito públicos, por exemplo, os casos de trabalhadores domésticos infantis e trabalho infantil em geral, e a servidão e trabalho escravo por dívida.

Ou também encontramos situação análoga à escravidão no aliciamento para a prática da prostituição, sobretudo de mulheres e meninas. Tal prática pode ocorrer dentro do seu próprio país, ou ainda, serem prostituídas fora dele, como "noivas por encomenda". Em outros casos, são atraídas para serem exploradas no turismo sexual, ou, quando não são destinadas à finalidade sexual, são submetidas a condições desumanas de trabalho (SOUTHARD, 2007, p. 380-381). São identificados como escravidão sexual, servidão marital e sexual, "tráfico internacional de mulheres e crianças para exploração sexual, o uso da internet para fins de exploração sexual, [...] e o comércio de crianças para prostituição e pornografia."(ROLLE, 2007, p. 341-342).

Ao nos depararmos com todas estas formas de injustiças praticadas contra o ser humano, perguntamo-nos, qual o papel da escola para evitar ou 
contribuir para a diminuição destas práticas? Obviamente, reconhecemos que a escola não possui domínio e poder suficiente para resolver essa questão, no sentido de eliminar radicalmente do indivíduo, o potencial para cometer injustiças. No entanto, como ela também não é neutra neste processo de construção da cultura, de valores e de princípios da sociedade, seria necessário investigar em que - ou de que forma - ela também poderia contribuir para minimizar esta latente propulsão para a barbárie, presente no ser humano e na sociedade como um todo.

\section{As lições de Auschwitz}

No intuito de entendermos um pouco mais sobre essa problemática da violência, Adorno nos convida para refletirmos acerca do ocorrido em Auschwitz, pois, evidentemente, temos muitas lições para tirarmos daquele episódio.

Primeiramente, se não entendermos as causas daquela tragédia, não teremos como evitá-la. Por outro lado, o que apavora é o fato de que ainda existem as condições que podem gerar este retrocesso no processo civilizatório da humanidade. "Apesar da não visibilidade atual dos infortúnios, a pressão social continuará se impondo. Ela impele as pessoas em direção ao que é indescritível e que, nos termos da história mundial, culminará em Auschwitz" (ADORNO, 1995, p.119).

Como já dissemos aqui, um contrassenso inacreditável que ficou evidente durante todo aquele genocídio, foi o fato de que a formação cultural recebida por aquela sociedade, tida como de altíssimo nível, e por mais que possamos considerá-la nobre hoje ainda, não conseguiu evitar tamanha insensibilidade. "O desenvolvimento da sociedade a partir da ilustração, em que cabe importante papel à educação e formação cultural, conduziu inexoravelmente à barbárie" (MAAR, 1995, p.11). É um paradoxo difícil de aceitar, o fato de que "[...] a civilização, por seu turno, origina e fortalece progressivamente o que é anticivilizador" (ADORNO, 1995, p.119). Em outros termos, também podemos concluir, tecnologicamente, avançamos bastante, todavia, interiormente, psicologicamente, continuamos os mesmos de sempre: invejosos, gananciosos e beligerantes.

Pensando ainda, especificamente acerca do Holocausto, a questão é que não podemos entender esse episódio como um fato isolado, um ponto fora da curva. Se "milhões de pessoas inocentes - [...] foram assassinadas de uma maneira planejada. Isto não pode ser minimizado por nenhuma pessoa viva" (ADORNO, 1995, p.120). O que fica difícil imaginar é que determinadas pessoas pudessem planejar, até mesmo usando métodos científicos, o extermínio de milhões de indivíduos, numa regressão à barbárie "e selvajaria de passadas eras 
- o qual, [...] poderia ter ocorrido na antiga Assíria ou em Roma? Mas no século $\mathrm{XX}$, as pessoas já não esperavam que tais coisas ainda pudessem acontecer" (ELIAS, 1997, p. 270).

Somando-se todos os judeus mortos entre 1939 e 1945, chegamos a números próximos de nove a dez milhões de pessoas. "Desses, cerca de 5 milhões foram fuzilados, gaseados, mortos pela fome ou de alguma outra forma condenados à morte." É uma realidade tão chocante que "quanto mais se conhecem os fatos, mais claro fica que as nossas explicações comuns fracassaram" (ELIAS, 1997, p. 275-276).

Portanto, temos de reconhecer que a tendência do progresso, ou do humanismo crescente falhou aqui. Isto fica evidente também nos dias atuais. "Como pode um mundo tão desenvolvido cientificamente apresentar tanta miséria?" Isto sem falarmos nas guerras e genocídios que ainda ocorrem, sem o nosso devido espanto (MAAR, 1995, p.15). Basta atentarmos para a naturalização com que observamos os conflitos após a Segunda Guerra. Podemos citar: a guerra das Coreias, do Vietnã, do Afeganistão, do Golfo, do Iraque, do Congo, da Síria; e tantos outros conflitos que ainda acontecem atualmente.

Diante da nossa passividade e da forma indiferente que a comunidade internacional reage: à morte e às vítimas de milhões nesses confrontos; à fome dos milhões de miseráveis transnacionais; e à crise humanitária que representam os refugiados nas diversas fronteiras do globo; só confirmam o colapso do nosso processo civilizatório.

Evidentemente que tal fato nos leva a concluir que existe algo de errado com a educação recebida, sobretudo, por quem tem poder de decisão. Ocorrenos então questionar: o que continua havendo de errado nessa educação oferecida, mesmo após o Holocausto? Uma vez que as evidências dão prova de que ela não está conseguindo influenciar, para evitar que tais atrocidades continuem acontecendo.

Este fracasso da cultura ocidental também é abordado pelo ativista da causa negra, Frantz Fanon, quando ironiza os benefícios do que se entende por inteligência.

Quando um outro tenta obstinadamente me provar que os negros são tão inteligentes quanto os brancos, digo: a inteligência também nunca salvou ninguém, pois se é em nome da inteligência e da filosofia que se proclama a igualdade dos homens, também é em seu nome que muitas vezes se decide seu extermínio.

$[\ldots]$

Ficaríamos muito felizes em saber que existe uma correspondência entre tal filósofo preto e Platão. 
Mas não vemos, absolutamente, em que este fato poderia mudar a situação dos meninos de oito anos que trabalham nas plantações de cana da Martinica ou de Guadalupe. (FANON, 1980 , p. 43 e 190).

Ou seja, a inteligência, como está posta, não necessariamente produz pessoas mais sensíveis às injustiças sociais.

Partindo do que ocorreu no Holocausto, Adorno suscita algumas causas ou propensões, dentro do indivíduo, que poderia ter favorecido para a ocorrência de tal barbárie. "[...] a disponibilidade em ficar do lado do poder, tomando exteriormente como norma curvar-se ao que é mais forte", é apontada como uma dessas causas. Neste sentido, "o único poder efetivo contra o princípio de Auschwitz seria autonomia." (ADORNO, 1995, p. 124-125).

$\mathrm{Na}$ sua reflexão acerca de como o homem se torna oprimido, e o que poderia ser feito para que ele se emancipasse, Freire também analisa essa questão da autonomia. Observa o educador que um ambiente familiar opressor pode inibir o desenvolvimento da autonomia, já desde a tenra infância da criança.

Crianças deformadas num ambiente de desamor, opressivo, frustradas na sua potência, como diria Fromm, se não conseguem, na juventude, endereçar-se no sentido da rebelião autêntica, ou se acomodam numa demissão total do seu querer, alienados à autoridade e aos mitos de que lança mão esta autoridade para formá-las, ou poderão vir a assumir formas de ação destrutiva. (FREIRE, 1987, p. 88).

Interessante percebermos essa associação que faz Freire. $O$ não desenvolvimento da autonomia pode desencadear em manifestações de "formas de ação destrutiva", ou seja, a propensão do indivíduo para uma violência instintiva.

O efeito nocivo da escola aqui está justamente em reforçar a perda dessa autonomia do educando, ao invés de resgatá-la. Tal fato, naturalmente, acaba repercutindo na sua vida adulta. Ao internalizar "a autoridade paterna através de um tipo rígido de relações, que a escola enfatiza, sua tendência, quando se fazem profissionais, pelo próprio medo da liberdade que neles se instala, é seguir os padrões rígidos em que se deformaram." (FREIRE, 1987, p. 88).

Outro traço psicológico que favoreceu a violência naquele contexto, foi o sadismo. Às vezes, passam despercebidos que até mesmo os trotes praticados nas escolas e universidades, ainda hoje, são próprios de sujeitos sádicos. Quando reconhecemos que "a brutalidade de hábitos tais como os trotes de qualquer ordem, ou quaisquer outros costumes arraigados desse tipo, é precursora imediata da violência nazista", percebemos o perigo nestas práticas. (ADORNO, 1995, p.128). 
Pensando em termos de se combater a barbárie e o sadismo, uma atividade humana que poderia concorrer nesse sentido seria a prática esportiva, sobretudo no ambiente escolar. Por um lado, essa prática pode desenvolver valores que vão ao encontro dessa busca, a de eliminar o instinto violento do ser humano. Virtudes tais como o cavalheirismo, o respeito ao mais fraco, e o fair play, entre outras, podem ser desenvolvidas nessa atividade humana. Por outro lado, aqueles que apenas assistem uma modalidade esportiva, podem ficar alheios a tudo isto, e "promover a agressão, a brutalidade e o sadismo" (ADORNO, 1995, p.127). É o que presenciamos, por exemplo, no futebol, numa copa do mundo, onde o fanatismo e o nacionalismo entram em cena, como um ingrediente a mais para alimentar o sadismo. Desta forma, a educação aqui teria a função primordial de, além de combater o sadismo, também de demonstrar todos os riscos de se alimentar o nacionalismo, de forma exacerbada. Visto que ele atua como estímulo para nossos instintos ufanistas mais primitivos.

Outra explicação possível para a violência manifestada pelos indivíduos, em ação ou por cumplicidade, consiste na fetichização da técnica. Em outros termos, é quando a pessoa fica tão hipnotizada pelos seus inventos, suas criações, suas técnicas, que ignora por completo, os malefícios que possa estar causando para as pessoas próximas, ou para a humanidade como um todo. Quando refletimos na função das indústrias armamentistas, de bebidas alcoólicas, de tabaco, comprovamos este feitiço sobre as pessoas. Esta fetichização da técnica é o que leva, por exemplo, uma pessoa a projetar "um sistema ferroviário para conduzir as vítimas a Auschwitz com maior rapidez e fluência, a esquecer o que acontece com estas vítimas em Auschwitz" (ADORNO, 1995, p.133).

A frieza, por sua vez, é também outra característica dos indivíduos que tendem a cometer atos de violência. Basta observarmos que os líderes nazistas eram pessoas que se distinguiam pela sua "incapacidade total de levar a cabo experiências humanas diretas, por um certo tipo de ausência de emoções, por um realismo exagerado" (ADORNO, 1995, p.129). Também nos dias atuais, observamos no noticiário atos de delinquência, crimes bárbaros cometidos por pessoas de sangue frio. Podemos definir o caráter desses sujeitos como de consciência coisificada. "No começo as pessoas desse tipo se tornam por assim dizer iguais a coisas. Em seguida, na medida em que o conseguem, tornam os outros iguais a coisas." São pessoas que "revelam traços de incomunicabilidade, no que se identificam com certos doentes mentais ou personalidades psicóticas." (ADORNO, 1995, p. 129-130).

Muitos atos abomináveis cometidos pelos seres humanos, somente foram possíveis graças a essa frieza. "[...] se as pessoas não fossem profundamente indiferentes em relação ao que acontece com todas as outras, [...] então Auschwitz não teria sido possível, as pessoas não o teriam aceito." Infelizmente somos sensíveis apenas às pessoas próximas do nosso convívio, sobretudo 
familiar, e provavelmente em função "de alguns interesses concretos" (ADORNO, 1995, p.133-134).

Não obstante, por óbvio, o caráter salutar e a indispensabilidade da vida familiar, para a criança e o adolescente, no seu processo de formação, à medida que o jovem vai se tornando adulto, convém que ele ultrapasse esse conceito de família. Pois, do contrário, como apontou Adorno, nossa preferência e preocupação pelo bem-estar, apenas dos entes familiares, funcionam como um alimento para o nosso egoísmo, no tocante a reforçar nossa indiferença em relação aos demais, sobretudo se estrangeiros.

Tal postura egoísta fica muito evidente, sobretudo, quando nos encontramos em situação de perigo, como foi no caso de Auschwitz. Ali ficou nítida a indiferença em relação aos demais.

Por mais nobres, honrados e amorosos, que normalmente nos julgamos, no entanto, em contextos de ameaça, de risco, agimos num salve-se quem puder. "A incapacidade para a identificação foi sem dúvida a condição psicológica mais importante para tornar possível algo como Auschwitz em meio a pessoas mais ou menos civilizadas e inofensivas." Neste sentido, portanto, fazse necessário "ajudar a frieza a adquirir consciência de si própria, das razões pelas quais foi gerada" (ADORNO, 1995, p. 134 e 136). Assim como, é preciso revelar às pessoas os mecanismos que as levam a cometer atos de brutalidade, "procurando impedir que se tornem novamente capazes de tais atos, na medida em que se desperta uma consciência geral acerca desses mecanismos" (ADORNO, 1995, p.121).

No intuito de impedir ou diminuir a probabilidade de outra barbárie, nas proporções de Auschwitz, como não temos controle sobre os fatores externos, nosso olhar deve se focar em como influenciar o lado subjetivo do indivíduo. Partindo do fato de que seja muito improvável se conseguir "mudar os pressupostos objetivos, isto é, sociais e políticos que geram tais acontecimentos, as tentativas de se contrapor à repetição de Auschwitz são impelidas necessariamente para o lado subjetivo" (ADORNO, 1995, p.121). Ou seja, neste sentido, a educação teria muito a contribuir, uma vez que ela, por princípio, seria uma das influências responsáveis na construção dessa subjetividade.

Toda a vida moderna, a ideia de civilização, num mundo capitalista, tende a valorizar pensamentos, sentimentos e ações, que, no fundo, em última instância, alimentam e promovem o egoísmo, a indiferença. Como observa Maar: "[...] o próprio processo que impõe a barbárie aos homens ao mesmo tempo constitui a base de sua sobrevivência" (1995, p.12). Portanto, combater esses valores "significa o mesmo que ser contra o espírito do mundo e desta maneira apenas repito algo que apresentei no começo como sendo o aspecto mais obscuro de uma educação contra Auschwitz" (ADORNO, 1995, p.133). 
Quando se diz da necessidade de se apelar para o lado subjetivo, significa mostrar para as pessoas os perigos que elas também correm, ao alimentarem esses valores nefastos. Ontem foram os judeus, negros e homossexuais. Mas nada impede que essa perseguição possa vir a ocorrer contra outros grupos, tais como: cristãos, imigrantes, não "arianos", não proprietários, entre outros. "Em última instância, qualquer pessoa não-pertencente ao grupo perseguidor pode ser atingida; portanto, existe um interesse egoísta drástico a que se poderia apelar." (ADORNO, 1995, p. 136- 137).

Reside nessa fala de Adorno, portanto, um flanco da subjetividade humana que a educação pode sim, buscar atingir. Demonstrar para o indivíduo que o seu interesse pelo direito de existir do grupo diferente ao seu, resulta da sua preocupação, mesmo que egoísta, do seu direito também de existir, podendo preservar sua diferença ante aos demais. Como diria Brecht, se não nos importarmos com os negros, operários, miseráveis, desempregados, ninguém, portanto, importar-se-á conosco, quando formos nós pertencentes ao grupo perseguido.

Se nos permitirmos ser condescendentes com nossos preconceitos, portanto, tornamos presas fáceis dos preconceitos dos outros, de um novo Auschwitz. Pois poderemos ser nós o grupo da vez, vítima da nova discriminação. Daí também a importância de nos libertarmos de todos os nossos preconceitos. "Quem não se liberta de seus preconceitos artísticos, científicos e políticos acaba fracassando, inclusive pessoalmente [...] Por isso, devemos nos aproximar da compreensão dos preconceitos partindo da esfera da cotidianidade." (HELLER, 1989, p. 43).

Outro ponto também a ser combatido é a noção de Estado que normalmente as pessoas possuem. $O$ indivíduo ao nascer e encontrar o Estado já constituído, com todo seu monopólio fiscal e poderio de força física sobre ele, tende a se portar, equivocada e preocupantemente, de maneira altamente submissa. Desta forma, faz-se necessário "tratar criticamente um conceito tão respeitável como o da razão de Estado [...] [Na] medida em que colocamos o direito do Estado acima do de seus integrantes, o terror já passa a estar potencialmente presente" (ADORNO, 1995, p.137).

Tratando da condição precária, que acomete uma vida, Butler também analisa essa violência praticada pelo Estado. "[...] [As pessoas] recorrem ao Estado em busca de proteção, mas o Estado é precisamente aquilo do que elas precisam ser protegidas. Estar protegido da violência do Estado-Nação é estar exposto à violência exercida pelo Estado-Nação". Em outros termos, "depender do Estado-Nação para a proteção contra a violência significa precisamente trocar uma violência potencial por outra." (BUTLER, 2017, p. 47).

Desta forma, o fato de uma sociedade depender e estar submissa ao Estado - como se evidencia, sobretudo, pela população mais carente - dificulta 
que ela mesma, por si só, reconheça ou conteste a violência praticada por Ele. Daí outra abertura que a educação precisa penetrar, conscientizar os indivíduos acerca da violência potencial, sempre iminente por parte do Estado, sobretudo quando the atribuímos mais poder do que Ele deveria receber.

No decorrer da história da humanidade vários artistas também lançaram seu olhar para a violência praticada pelo Estado, quer seja contra sua própria população, ou contra a de outro povo. Como exemplo, poderíamos citar a obra Guernica, de Pablo Picasso, de 1937, que retrata o massacre de crianças e mulheres na guerra civil espanhola, pelos defensores do General Franco. Assim como, o quadro O fuzilamento de 03 de maio de 1808 em Madri, pintado por Goya, que retratou a morte de revoltosos da população madrilena, contra a invasão francesa. Ambos os artistas representaram e interpretaram em suas pinturas os horrores da guerra. Temos também aqui na América Latina, sobretudo no período das ditaduras militares, o estilo musical que ficou conhecido como músicas de protesto. Tal estilo teve vários artistas de expressão, como Chico Buarque, Caetano Veloso, Gilberto Gil, Mercedes Sosa, Facundo Cabral, Victor Jara, entre outros. Esses artistas tinham também este propósito, criticar a mão pesada do Estado que oprimia e reprimia, principalmente a liberdade de expressão.

Portanto, talvez até mais que a arte - que por essência, no seu processo de criação, não pode ter nenhum compromisso que a engesse - a educação, indubitavelmente, também tem esse papel de contribuir para a conscientização das arbitrariedades cometidas pelo Estado, sobretudo nos governos totalitários.

Outra sugestão que podemos encontrar na obra de Adorno, no intuito de evitarmos uma nova barbárie, seria a de revisitar o passado, no sentido de reelaborá-lo, para que as gerações presentes e vindouras tenham consciência plena do ocorrido, e, desta forma, busquem evitá-lo veementemente.

Temos de reconhecer o fato de que "[...] a memória, o tempo e a lembrança são liquidados pela própria sociedade burguesa em seu desenvolvimento, como se fossem uma espécie de resto irracional" (ADORNO, 1995, p. 33). Assim como, termos clareza de que esse esquecimento não ocorre por acaso. Há uma intenção muito bem definida nisto. A memória somente é exercida quando há um interesse político por trás, por exemplo, realiza-se a rememoração de peripécias da história, porque elas são tidas "como os acontecimentos fundadores da identidade comum” (RICCEUR, 2007, p. 98).

Geralmente, "apagar a memória seria muito mais um resultado da consciência vigilante do que resultado da fraqueza da consciência frente à superioridade de processos inconscientes" (ADORNO, 1995, p. 33). Porém, por mais que se tente, o passado permanece, e o perigo dele se repetir também, talvez porque não foram devidamente eliminados os fatores que 0 desencadearam. "O encantamento do passado pôde manter-se até hoje 
unicamente porque continuam existindo as suas causas" (ADORNO, 1995, p. 49).

Esse encantamento justamente revela que, dependendo da forma como o passado é referido no presente, poderemos ter uma postura distinta em relação a ele. "Se permanecemos no simples remorso ou se resistimos ao horror com base na força de compreender até mesmo o incompreensível. Naturalmente que para isto será necessária uma educação dos educadores" (ADORNO, 1995, p. 46). Com certeza, conscientizar o educador acerca da necessidade de ele compreender as causas de Auschwitz, e também do seu papel para evitar um novo horror, é uma das tarefas mais difíceis.

Fica evidente, portanto, a importância dada para o que se denomina como memória coletiva, uma vez que esse tipo de memória é objeto de luta das forças sociais pelo poder. "Tornarem-se senhores da memória e do esquecimento é uma das grandes preocupações das classes, dos grupos, dos indivíduos que dominaram e dominam as sociedades históricas." De tal forma que "os esquecimentos e os silêncios da história são reveladores desses mecanismos de manipulação da memória coletiva" (LE GOFF, 1990, p. 426).

Ainda teríamos que nos debruçar acerca das seguintes questões, ao buscamos entender o passado. Abordaremos o passado pela "memória dos protagonistas da ação tomados um a um, ou a das coletividades tomadas em conjunto? [...] a memória é primordialmente individual ou coletiva?" (RICCEUR, 2007, p. 105). É claro que o presente trabalho não permite desenvolvermos tais respostas, todavia, por meio destas perguntas conseguimos ter uma ideia da complexidade que envolve esta questão. O olhar do educador deve estar consciente de todo filtro que realiza, de todas as escolhas que elabora, quando necessita trazer à tona o passado.

Não obstante, temos de reconhecer que "a memória, onde cresce a história, que por sua vez a alimenta, procura salvar o passado para servir o presente e o futuro". Portanto, o nosso trabalho consiste em fazer com que "a memória coletiva sirva para a libertação e não para a servidão dos homens" (LE GOFF, 1990, p. 477).

A situação incômoda, do passado mal resolvido, por diversas vezes vem à tona, "seja por parte dos pais que enfrentam a desagradável pergunta acerca de Hitler por parte de seus filhos e que, inclusive para se inocentar, remetem ao lado bom e que propriamente não foi tão terrível assim" (ADORNO, 1995, p. 45). O fato é que numa guerra, "a glória de uns foi a humilhação para outros. À celebração, de um lado, corresponde à execração, do outro. Assim se armazenam, nos arquivos da memória coletiva, feridas simbólicas que pedem uma cura." (RICCEUR, 2007, p. 92).

Fanon, o ativista negro da Martinica, fala-nos com propriedade desta ferida do passado, provocada pelo período de escravidão de seu povo.

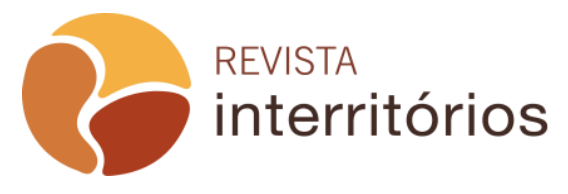


Então não tenho outra coisa a fazer nesta terra senão vingar os negros do século XVII? [...]

Vou exigir do homem branco de hoje que se responsabilize pelos negreiros do século XVII?

Vou tentar por todos os meios fazer nascer a Culpabilidade nas almas? A dor moral diante da densidade do Passado? Sou preto, e toneladas de grilhões, tempestades de pancada, torrentes de escarro escorrem pelas minhas costas. [...]

Mas, eu, homem de cor, na medida em que me é possível existir absolutamente, não tenho o direito de me enquadrar em um mundo de reparações retroativas. (FANON, 1980, p. 188 e 191).

Portanto, ao se reelaborar o passado, devemos levar em conta tudo isto. Buscar a conscientização que nos aponta Adorno, acerca de todo o horror que ele pode ter sido, porém, sem cairmos no revanchismo, no olho por olho dente por dente, como nos ensina Fanon. A intenção é que tenhamos os erros do passado, vivos, justamente para que não incorramos no mesmo ódio que levou aquelas ações. E não trazê-los para o presente, na intenção de alimentar um novo ódio, numa outra forma de preconceito, num revanchismo interminável.

Outra causa que também poderia propiciar atitudes de violência, encontramos em Adorno no que ele define por semicultura. Mesmo reconhecendo que esse fator vai muito além dos muros da escola, convém nos debruçarmos sobre ele.

A crise de formação cultural que se passa atualmente, não pode ser objeto de estudo apenas da pedagogia, e nem tampouco pode ser deixada a cargo somente da sociologia. Quando nos atentamos para "os sintomas de colapso da formação cultural que se fazem observar por toda parte, mesmo no estrato das pessoas cultas," e que sabemos não advém apenas das "insuficiências do sistema e dos métodos da educação"; assim como, quando constatamos que são "insuficientes as reflexões e investigações isoladas sobre os fatores sociais que interferem positiva ou negativamente na formação cultural" (ADORNO, 2010, p. 8), fica evidente a necessidade de um estudo multidisciplinar para buscar entender esta questão.

O fato de a semiformação caracterizar toda ilustração e informação que se difunde, e ter se tornado a forma da consciência atual, "exige uma teoria mais abrangente" (ADORNO, 2010, p. 9), uma vez que a erudição ou a civilização ocidental, da maneira como vem sendo concebida, ou como se deseja que ela seja preconizada ou imposta, não necessariamente humaniza, por mais estranho que isso possa soar. É surpreendente, por exemplo, constatar que muitas pessoas afeitas a uma obra de arte, à música, sensíveis à cultura artística, mesmo assim, possam ser indiferentes a seus pares, insensíveis aos outros seres humanos. Adorno relata que na época do nazismo, "Max Frisch observou que havia pessoas que se dedicavam, com paixão e compreensão, aos 
chamados bens culturais, e que, no entanto, puderam se encarregar tranquilamente da práxis assassina do nacional-socialismo." Em outros termos, ocorre aqui uma dissociação dos bens culturais da "implantação das coisas humanas. A formação que se esquece disso, que descansa em si mesma e se absolutiza, acaba por se converter em semiformação" (ADORNO, 2010, p. 10).

Cabe destacar que, na origem, o homem traz consigo uma natureza agressiva. Neste sentido, primeiramente, a formação teve como propósito "domesticar o animal homem mediante sua adaptação interpares". Desta forma, "pela pressão que [esta adaptação] exerce sobre os homens, perpetua neles o não-formado [a deformidade] que se pensava ter-se formado [dominado]: a agressão. Este é, conforme Freud o vê, o fundamento do mal-estar na cultura" (ADORNO, 2010, p.11).

Desde o início, a formação foi concebida numa série de contradições. Pensava-se que ela seria condição implícita para uma sociedade autônoma, para formar homens livres, numa sociedade livre, racionais numa sociedade racional. A contradição consiste no caráter subjetivo da cultura - fonte primária da formação - que trai a si mesma, provocando o oposto do que ela mesma intenta produzir. "O sonho da formação [...] é falsificado em apologia de um mundo organizado justamente por aquela imposição. No ideal de formação, que a cultura institui de maneira absoluta, destila-se o caráter duvidoso da cultura." (ADORNO, 2010, p. 13-14).

Nesse momento, também nos ocorre aquelas circunstâncias em que houve imposição cultural, no decorrer da história da humanidade, nas investidas realizadas pelos europeus contra o continente africano, com o intuito de "civilizálo".

Condorcet sublinha em seguida, os benefícios de uma colonização espiritual e cultural civilizadora. Aos monges que, nesses países, só traziam vergonhosas superstições, devem suceder homens ocupados em propagar, entre essas nações, as verdades úteis à sua felicidade e capazes de esclarecê-los tanto sobre seus interesses quanto sobre seus direitos. (FOÉ, 2013, p. 191).

Du Bois, outro expoente da causa negra, descreve mais diretamente a violência cometida nessa ação do colonizador. Observa que esta ideologia, de se pregar o negro ou o continente africano como um todo primitivo, deriva de preconceitos tais como: "a defesa natural da cultura contra o barbarismo, do saber contra a ignorância, da pureza contra o crime, das raças 'superiores' contra as 'inferiores'” (1999, p. 59).

Portanto, caberia à educação apontar as consequências nefastas que a semicutura pode causar. Uma delas é essa, a imposição cultural explicitada nas contradições cometidas pelos europeus. Uma vez que, quando buscavam

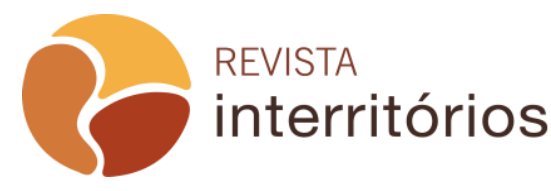

Interritórios | Revista de Educação Universidade Federal de Pernambuco, Caruaru, BRASIL | V.6 N.10 [2020] 
"civilizar" os povos africanos, por meio do etnocentrismo, estavam sendo mais bárbaros do que aqueles que eles queriam civilizar.

Freire também descreve as aberrações desta forma de violência, quando retrata a imposição cultural dos opressores sobre os oprimidos.

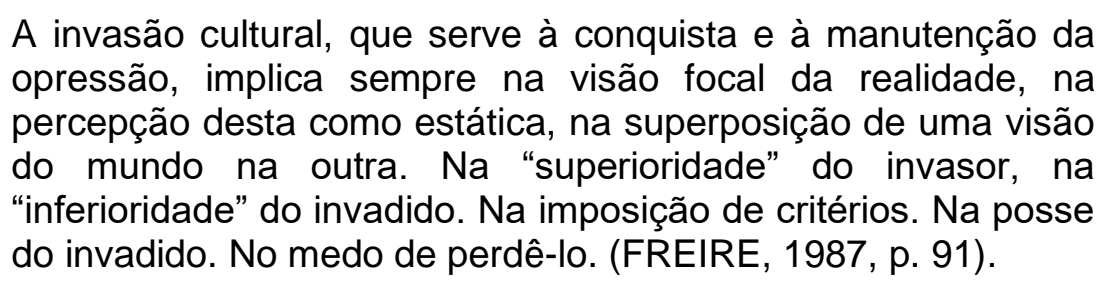

Ou seja, para além da colonização tradicional, com a ocupação física de um país sobre o outro, a invasão cultural descrita por Freire, também acontece como imposição de uma visão de mundo sobre outra, no sentido da predominância da classe dominante sobre a submissa. A mesma lógica que fica evidente aqui, é claro, é a da imposição cultural praticada no etnocentrismo.

E cabe ainda destacar nesse tópico, outro aspecto a ser considerado pelo educador, que citamos de Adorno. A formação cultural que se esquece de estar atrelada com as "coisas humanas", identificada com a fetichização da técnica, converte-se em semiformação.

\section{A formação humana integral}

Por fim, chegamos a essa parte do nosso trabalho com a seguinte reflexão, existe uma qualidade de cultura que de fato propicie a formação humana, no sentido de despertar a sensibilidade humana?

Partindo de toda contestação que Adorno faz acerca da pseudoformação, e da necessidade de uma formação real, encontramos um paralelo com o que era defendido por Gramsci, e atualmente se concebe como sendo a formação humana integral. Nos seus manuscritos realizados no cárcere, o autor italiano descreve como ele concebia uma escola com esse propósito.

A escola unitária ou de formação humanista (entendido este termo, "humanismo", em sentido amplo e não apenas em sentido tradicional), ou de cultura geral, deveria assumir a tarefa de inserir os jovens na atividade social, depois de tê-los elevado a um certo grau de maturidade e capacidade para a criação intelectual e prática e a uma certa autonomia na orientação e na iniciativa. (GRAMSCI, 1968, p. 121).

Inspirados nessas ideias de Gramsci, que concebia a educação como um todo, no sentido de formar o trabalhador não apenas para a fábrica, mas também

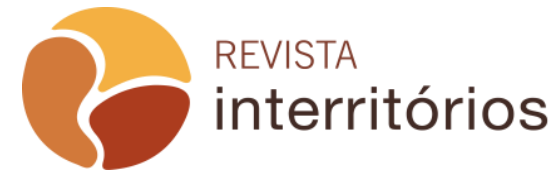


porta voz de uma consciência crítica, observamos o conteúdo de algumas políticas educacionais aqui no Brasil.

Alguns documentos tiveram esse propósito, isto é, promover uma formação humana integral. Podemos destacar: as Diretrizes Curriculares Nacionais para o Ensino Médio, as diretrizes para o Ensino em Direitos Humanos, e o Programa Ensino Médio Inovador; entre outras ações governamentais com essa intenção.

A Educação em Direitos Humanos é muito cara à formação humana integral, uma vez que ela tem "por escopo principal uma formação ética, crítica e política” (BRASIL, 2014a, p. 522). Quando observamos que esta formação que fundamenta a Educação em Direitos Humanos, também compreende princípios, tais como: a defesa da dignidade humana; a igualdade de direitos; 0 reconhecimento e valorização das diferenças e das diversidades; a laicidade do Estado; a democracia na educação; transversalidade, vivência e globalidade; e a sustentabilidade socioambiental; somente confirmam a sua relevância para a formação humana integral. (BRASIL, 2014a, p. 522-523).

Para que a formação humana integral do sujeito se realize, concebe as DCNEMs $^{3}$, requer que a educação seja focada em várias dimensões. As dimensões do "trabalho, da ciência, da tecnologia e da cultura, podem contribuir para explicitar o significado da formação na etapa conclusiva da Educação Básica, uma vez que materializa a formação humana integral" (BRASIL, 2014b, p. 190).

O Programa Ensino Médio Inovador, da mesma forma, buscou dar vida as diretrizes acima citadas, dispondo também, sobre como pode ser a formação humana integral na prática escolar. Nesse tipo de formação, a educação valoriza "a capacidade de o indivíduo tornar-se autônomo intelectual e moralmente, isto é, de ser capaz de interpretar as condições histórico-culturais da sociedade em que vive e impor autonomia às suas próprias ações e pensamentos" (BRASIL, 2013c, p. 32).

É fundamental termos em mente que "o respeito à autonomia e à dignidade de cada um é um imperativo ético e não um favor que podemos ou não conceder uns aos outros" (FREIRE, 1996, p. 59). Desta forma, "[...] ou a educação escolar se destina à formação para a autonomia ou ela não é capaz de ultrapassar a mera adaptação dos indivíduos à sociedade." (BRASIL, 2013c, p. 33).

Gramsci, pensando na autonomia mais como um método, descreve assim o aprendizado nessas circunstâncias.

${ }^{3}$ Diretrizes Curriculares Nacionais para o Ensino Médio.

\begin{tabular}{l|l} 
REVISTA & interritórios
\end{tabular} $\begin{aligned} & \text { Interritórios | Revista de Educação } \\
& \text { Universidade Federal de Pernambuco, } \\
& \text { Caruaru, BRASIL | V.6 N.10 [2020] }\end{aligned}$


[...] escola criadora [...] indica que a aprendizagem ocorre notadamente graças a um esforço espontâneo do discente, e no qual o professor exerce apenas uma função de guia amigável, como ocorre ou deveria ocorrer na universidade. Descobrir por si mesmo uma verdade, sem sugestões e ajudas exteriores, é criação (mesmo que a verdade seja velha) e demonstra a posse do método; indica que, de qualquer modo, entrou-se na fase da maturidade intelectual na qual se pode descobrir verdades novas. (GRAMSCI, 1968, p. 124-125).

Prestigiar essa autonomia no educando, com certeza, contribui para que ele não seja facilmente manipulável, sobretudo nas situações limites em que se exigirá dele, decisão por com consciência própria.

A formação humana integral que estamos tratando aqui, concebida por Gramsci, inspirado em Marx, também é definida como uma formação omnilateral. Trata-se, portanto, "de um desenvolvimento total, completo, multilateral, em todos os sentidos, das faculdades e das forças produtivas, das necessidades e da capacidade da sua satisfação." (MANACORDA, 2007, p. 94). Uma formação humana integral, baseada na omnilateralidade, concebe que na formação do ser humano deve-se buscar desenvolvê-lo "em todas as suas potencialidades, por meio de um processo educacional que considere a formação científica, tecnológica e humanística, a política e a estética, com vistas à emancipação das pessoas". Esta qualidade de formação "implica em competência técnica e compromisso ético, que se revelem em uma atuação profissional pautada pelas transformações sociais, políticas e culturais necessárias à edificação de uma sociedade igualitária." (BRASIL, 2013d, p. 34).

Quando dizemos acima que essa espécie de formação contempla também um compromisso ético, inevitavelmente nos ocorre a preocupação de Freire, nesse sentido.

Da ética que condena [...] a exploração da força de trabalho do ser humano, que condena acusar por ouvir dizer, afirmar que alguém falou $A$ sabendo que foi dito $B$, falsear a verdade, iludir o incauto, golpear o fraco e indeciso, soterrar o sonho e a utopia, prometer sabendo que não cumprirá a promessa, testemunhar mentirosamente, falar mal dos outros pelo gosto de falar mal. (FREIRE, 1996, p. 16).

Preocupar-se com uma formação ética é um dos princípios fundamentais da educação. $E$ evidentemente também que, em toda situação de guerra, de barbárie, de violência, as primeiras vítimas são a honestidade e o compromisso ético.

Portanto, das inferências que podemos fazer a partir das leituras dos autores aqui tratados, entre outros pensadores da educação, não nos dá margem para que possamos afirmar categoricamente o que é a formação 
humana integral, uma vez que ela possui várias concepções. Todavia, podemos talvez sugerir qual pode ser a postura mais esperada do professor, que tem essa qualidade de formação como princípio e objetivo, sobretudo no que diz respeito à sua preocupação em desenvolver a autonomia no outro. Que respeite o educando, na sua mais fundamental dignidade, de ser humano que é; que busque aprender com o educando, se formar enquanto estiver formando; que não imponha suas convicções e conclusões ao educando, mas compartilhe conhecimento com ele; que não entregue a resposta pronta, sem o deixar pensar; que instigue sua curiosidade; que não seja prescritivo; que saiba ficar mais em silêncio e ouvi-lo; que forneça ao educando condições de autogoverno, para que ele próprio possa assumir as rédeas do seu processo de formação; que não veja o erro como algo a ser punido, mas sim, como um instrumento de diagnóstico, um meio para a virtude; enfim, que crie condições para que o educando chegue a suas próprias descobertas, por meio de um experimento de qualidade, facultado por ele, o educador.

Como diria Paulo Freire e Adorno, a educação só poderá ser transformadora educando o educador. Do contrário, mudar apenas o padrão ou o sistema de ensino não fará diferença.

\section{Considerações finais}

Por fim, após todas essas reflexões, alguns entendimentos ficaram mais vivos na nossa compreensão. O primeiro deles é que, sem dúvida, o quanto as circunstâncias que envolveram Auschwitz têm muito a nos ensinar. Tornou-se evidente que o desenvolvimento tecnológico ou a formação cultural sofisticada, não necessariamente tornam as pessoas melhores. O constrangimento de ter que se deparar e lidar com o mal-estar da cultura ficou indisfarçável. Saltou-nos aos olhos, a invasão, imposição, e violência cultural praticada por aquele que se entende como "civilizador". Explicitaram-se as consequências nefastas que pode ocasionar o condicionamento social, por meio de ideologias, dogmas, e propagandas tão obscurantistas, a ponto de levar um coletivo de pessoas a cometerem as atrocidades mais repugnantes possíveis.

Por outro lado, essas reflexões também nos servem pelo seguinte motivo. Como podemos constatar, no episódio da fala do Secretário de Cultura do governo brasileiro, e também como observa Adorno, infelizmente, as causas para que um novo Auschwitz aconteça ainda estão entre nós. As mesmas índoles nos governantes, e os mesmos ímpetos na sociedade, para a barbárie, ainda vemos sendo manifestadas diariamente.

Desta forma, fica evidente também o quanto devemos revisitar o passado, trazê-lo à tona. Não permitir que ele seja esquecido. Mantê-lo vivo na 
consciência das pessoas, como um trauma a ser evitado, talvez seja essa também a função deste nosso artigo.

Daí também, portanto, recorrermos ao sistema de ensino, como sendo uma das medidas possíveis, para se buscar corrigir os rumos de uma nova tragédia. Nesse sentido, como dissemos aqui, vários aspectos podem ser observados na educação, no afã de que ela não continue sendo cúmplice, das barbáries praticadas até os dias atuais.

Tomando como base as pistas que podemos inferir das reflexões de Adorno, fica evidente a necessidade de um trabalho em ampla frente, para se evitar uma nova barbárie. Os três grandes atores deste processo educativo deveriam se engajar. O Estado, não apenas na criação, mas também na indução, e na valorização de políticas públicas educacionais com esta concepção, isto é, de objetivar a formação humana integral como um princípio sine qua non. Os docentes, por meio de uma formação contínua, e de qualidade, serem conscientizados do quanto a sua prática escolar - se estiver atenta aos aspectos que refletimos aqui - pode influenciar numa formação mais humanizadora e empática, para o educando. E complementando esta dinâmica, temos também os educandos, que no processo de ensino e aprendizagem, podem contribuir retroalimentando a conscientização dos valores, desenvolvidos na formação humana integral.

O fato é que, partindo das ideias que nos apontam os autores citados, se a educação não conseguir dar conta de formar indivíduos que se conscientizem, entre outras concepções, acerca da necessidade de se combater 0 nacionalismo, xenofobia, etnocentrismo, racismo, as injustiças sociais de toda ordem, a competitividade predadora, os preconceitos em geral, a discriminação, os trotes, o bullying; indivíduos que respeitem a diversidade, as diferenças étnico-raciais, as pessoas com necessidades especiais; que valorizem a alteridade, as liberdades individuais; uma educação que tenha como princípio desenvolver a autonomia, respeitando a dignidade da existência do indivíduo; entre outros valores e concepções que promovam uma formação humana, no sentido de desenvolver um ser humano realmente sensível aos seus pares, dificilmente a educação conseguirá contribuir para evitar uma nova barbárie, um novo Auschwitz.

Por outro lado, pode-se dizer de uma forma paradoxal que, assim como a luta pela liberdade, carece da falta de liberdade, da mesma forma, a educação, no sentido de formação humana integral ou formação real - como concebe Adorno - sempre será necessária, sobretudo enquanto persistirem as condições que objetivamente a neguem.

\section{REFERÊNCIAS}


ADORNO, Theodor W. cap. O que significa elaborar o passado e Educação após Auschwitz in: Educação e emancipação. 2 ed. SP: Paz e Terra. 1995.

ADORNO, Theodor W. Teoria da semiformação. In: Pucci, B; Zuin, A. Lastória (orgs). Teoria Crítica e inconformismo. Novas perspectivas de pesquisa. São Paulo: Cortez, 2010.

BRASIL, Secretaria de Educação Básica. Formação de Professores do ensino médio, etapa I. Caderno III: o currículo do ensino médio, seu sujeito e o desafio da formação humana integral. Curitiba: UFPR/Setor de Educação, 2013c.

BRASIL, Secretaria de Educação Básica. Formação de Professores do ensino médio, etapa I. Caderno I: ensino médio e formação humana integral. Curitiba: UFPR/Setor de Educação, 2013d.

BRASIL, MEC. Diretrizes Curriculares Nacionais para a Educação em Direitos Humanos. In: Diretrizes Curriculares Nacionais da Educação Básica. 2014a. Disponível em:

http://portal.mec.gov.br/index.php?option=com docman\&view=download\&alias $=15548$ -d-c-n-educacao-basica-nova-pdf\&category slug=abril-2014-pdf\&ltemid=30192 Acesso em: 21 jan 2020.

BRASIL, MEC. Diretrizes Curriculares Nacionais para o Ensino Médio. In: Diretrizes Curriculares Nacionais da Educação Básica. 2014b.

Disponível em:

http://portal.mec.gov.br/index.php?option=com docman\&view=download\&alias $=15548$ -d-c-n-educacao-basica-nova-pdf\&category slug=abril-2014-pdf\&ltemid=30192

Acesso em: 21 jan 2020.

BUTLER, Judith. Quadros de Guerra: quando a vida é passível de luto? Rio de Janeiro: Civilização brasileira, 2017.

ELIAS, Norbert. Os alemães. A luta pelo poder e a evolução do habitus nos séculos XIX e XX. Rio de Janeiro: Zahar, 1997.

FANON, Frantz. Pele negra, máscaras brancas. Rio de Janeiro: Fator, 1980.

FOÉ, Nkolo. África em diálogo, África em autoquestionamento: universalismo ou provincialismo? "Acomodação de Atlanta" ou iniciativa histórica? In: Educar em Revista. Curitiba: UFPR, n. 47, p. 175-228, jan./mar. 2013.

FREIRE, Paulo. Pedagogia do oprimido. Paz e Terra, 1987.

FREIRE, Paulo. Pedagogia da autonomia. Paz e Terra, 1996.

GRAMSCI, Antonio. Os intelectuais e a organização da cultura. Rio de Janeiro: Civilização Brasileira, 1968.

HELLER, Agnes. O cotidiano e a história. (3. Ed.) Rio de Janeiro: Paz e Terra, 1989.

LE GOFF, Jacques. História e memória. São Paulo: Unicamp, 1990. 
MANACORDA, Mario Alighiero. Marx e a pedagogia moderna. (Tradução: Newton Ramos de Oliveira). Campinas: Alínea, 2007.

MARR, Wolfgang Leo. À guisa de introdução: Adorno e a experiência formativa. In: ADORNO, Theodor W. Educação e emancipação. 2 ed. São Paulo: Paz e Terra, 2000.

RICCEUR, Paul. A Memória, a história, o esquecimento. Campinas: Unicamp, 2007.

ROLLE, Baptiste. Escravidão. In: POOLE, Hilary (Org.) et al. Direitos humanos: referências essenciais. São Paulo: Edusp, 2007. 